\title{
Uma ocupação estudantil como máquina de guerra: redes sociais como instrumento de resistência
}

\section{A student occupation as war machine: social media as a tool of resistance \\ Una ocupación estudiantil como máquina de Guerra: Las redes sociales como instrument de Resistencia}

\author{
Douglas Feitosa Romão \\ Universidade Federal Fluminense - UFF - Brasil \\ ORCID: https://orcid.org/0000-0002-1347-2782 \\ Endereço currículo Plataforma Lattes: http://lattes.cnpq.br/9901778793006136 \\ E-mail: romao.doug@gmail.com
}

Resumo: Apresentamos a partir deste artigo uma leitura possível do uso de mídias sociais e fotografias produzidas ou garimpadas online por estudantes secundaristas durante o movimento de escolas ocupadas em São Paulo ocorrida de novembro de 2015 a janeiro de 2016 em oposição ao plano de reorganização escolar. Para tanto, observamos a página correspondente à Escola Estadual Fernão Dias Paes "Escola de luta Fernão Dias Paes" no Facebook. Utilizamos os conceitos de liso e estriado de Deleuze \& Guattari com vista a refletirmos sobre a dinâmica daquela ocupação e algumas de suas potencialidades de resistência e pontos de fuga.

Palavras-chave: Redes sociais. Deleuze. Guattari. Ocupação. Educação.

Abstract: This paper relates to a possible understanding of social media and photographs produced or found online by high school students during the occupied schools movement in São Paulo occurred from November 2015 to January 2016 opposing to a reorganizing school plan. We observe the page which corresponds to Fernão Dias Paes State School movement "Escola de luta Fernão Dia Paes" on Facebook. We discuss the Deleuze's concepts of smooth and striated regarding the dynamics of that occupation and some of its potentialities of resistence and vanishing points.

Keywords: Social networks. Deleuze. Guattari. Occupation. Education. 
Resumen: En este articulo presentamos una posible lectura de los usos de los medios sociales y las fotografías producidas o encontradas en línea por estudiantes secundaristas durante el movimento de las escuelas ocupadas en São Paulo ocurrido desde noviembre de 2015 hasta enero de 2016. Por lo tanto hemos observado a la página que corresponde a la Escuela Estatal Fernão Dias Paes "Escola de luta Fernão Dias Paes" en el Facebook. Nosostros hemos utilizado los conceptos de liso y estriado de Deleuze con el fin de reflejar acerca de la dinámica de aquella ocupación y algunas de sus potencialidades de resistência y puntos de fuga.

Palabras-clave: Redes sociales. Deleuze. Guattari. Ocupación. Educación.

\section{Breve histórico}

As ocupações como método de reivindicação pelos secundaristas paulistas iniciaram-se após sequência de manifestações ocorridas no mês de outubro de 2015. Tratava-se de oposição à chamada "reorganização escolar", promovida pela Secretaria de Educação do Estado de São Paulo, cujo objetivo seria obter condições estruturais e pedagógicas para "articular espaço e tempo a favor do currículo", nas palavras do então secretário de educação Herman Voorwald (2015). Para isso, converteriam escolas de diversos ciclos em escolas de ciclo único, promovendo fechamento de salas supostamente ociosas, remanejamento de estudantes para zonas próximas, e, em alguns casos, até mesmo o fechamento de escolas disponibilizando-as a outros usos. Na crítica dos secundaristas, o poder público não havia discutido com a sociedade a respeito do projeto, fazendo assim um esforço de cima para baixo a fim de que a reorganização fosse concretizada, o que levou à desinformação sobre os efeitos concretos de tal mudança. Após sequência de manifestações desde o início de outubro de 2015, secundaristas organizaram-se autonomamente tendo como método o uso de ocupações de suas escolas para obterem visibilidade e disputa com o governo do Estado.

A primeira escola a ser ocupada foi a Escola Estadual Diadema em 09/11, no Grande ABC. Sua página no Facebook iniciou-se em 08/10 como “Ocupa E. E. Diadema" e passou a promover manifestações nos dias que se seguiram. No dia seguinte à primeira ocupação, a Escola Estadual Fernão Paes Dias, no bairro de Pinheiros na capital paulista, foi também ocupada. Outras agremiações estudantis seguiram o modelo de disputa e passaram a ocupar suas escolas em todo o estado, 
Uma ocupação estudantil como máquina de guerra: redes sociais como instrumento de resistência

ROMÃO, 2019

atingindo mais de 200, que a partir de então passaram a se articular através de um "Comando das escolas em luta". O projeto de reorganização foi suspenso em 04/12 seguido da disponibilização do cargo do secretário de educação. Apesar disso, os secundaristas não abandonaram as ocupações imediatamente, pois esta decisão foi deixada às assembleias estudantis em cada escola ocupada. Durante as ocupações foram promovidas aulas públicas, debates e encontros diversos, com artistas e oficineiros. Passados muitos meses as escolas envolvidas nas ocupações ainda promoviam encontros a partir do "Comando das escolas em luta" a fim de discutir a revogação do projeto de reorganização que fora suspenso. Porém, segundo afirmaram, a reorganização continuou sendo feita escola a escola. A politização de estudantes secundaristas ainda ressoa em 2019 com grupos como "Secundaristas em luta de SP".

O movimento de escolas ocupadas em São Paulo ocorreu de novembro de 2015 a janeiro de 2016. A Escola Estadual Fernão Dias Paes e sua página no Facebook foram escolhidas devido ao manejo de fotografias e sua organização ter explorado as redes sociais: em uma semana foi aberta uma página na rede Facebook chamada "Ocupa Fernão" que após a organização do "Comando de escolas em luta" passou a ser "Escola de luta Fernão Dias Paes"1. Além disso, a repercussão conseguida em diversos veículos de comunicação, como capas de jornais e telejornais, inclusive sendo tema de uma telenovela juvenil da Rede Globo. Sua durabilidade, também, extrapolou a maioria das outras ocupações, durando 55 dias, e parte de seus ocupantes, mas não apenas, seguiram com destaque nas manifestações contra o aumento das tarifas dos transportes coletivos ocorridas ao longo do mês de janeiro ${ }^{2}$. Então, para a coleta de nosso material fotográfico, observamos a página que corresponde à Escola Estadual Fernão Dias Paes no Facebook, desde sua ativação até o último dia de ocupação escolar, isto é, de 17 de novembro 2015 a 5 de janeiro de 2016.

\section{A instituição escolar como espaço estriado e a relação com o espaço liso estudantil}

Gostaríamos de propor inicialmente uma análise possível da instituição escolar e sua relação com o corpo discente através dos conceitos de espaço estriado e espaço liso de Deleuze \& Guattari tal como expõem na obra Mil platôs. A instituição escolar tem como característica o lugar da norma, da regra, da disciplina que opera um regime 
Uma ocupação estudantil como máquina de guerra: redes sociais como instrumento de resistência

ROMÃO, 2019

pedagógico sob o qual alunos sofrem um processo de docilidade-utilidade, para utilizar o termo foucaultiano, ou de certa forma a administração da passagem da juventude à vida adulta e sua inserção no modo de vida capitalista, na máquina capitalista. A instituição escolar tendo como origem o aparato da vigilância, da divisão espacial, e hierarquização, em sua versão moderna funciona como uma máquina de ensino que "não comunica, mas impõe à criança coordenadas semióticas", para Deleuze \& Guattarri (2004) o professor "ensigna, dá ordens, comanda". Como diz Carvalho \& Camargo (2015, p. 109), um "garoto em idade escolar encontra na própria subjetividade maquínica um processo de agenciamento coletivo de enunciação". Disso depreende-se que um processo pedagógico numa instituição escolar se dá por agenciamentos, de modo que a escola opera uma máquina política que investe os alunos na escolarização.

Podemos relacionar esse espaço institucional da escola como o "espaço estriado", o espaço das regras onde se desenvolve o instituído pelos aparelhos de Estado. Por outro lado, haveria um espaço discente que seria equivalente ao espaço liso, locus da quebra de disciplina, da diversão, do gozo. A saber, diz Deleuze \& Guattari (2004; 1997), esses espaços se relacionam por vezes como um conjunto de oposições simples e de diferenças complexas, fazendo com que termos sucessivos das oposições consideradas nem sempre coincidem, estabelecendo também correlações não-simétricas. Apesar de nossa exposição não esgotar a complexidade dos conceitos, almejamos reconhecer a instituição escolar como um pretenso espaço diretor do espaço liso, espaço estriado que a todo momento disciplina o corpo discente a ser parte de seu maquinário, cuja finalidade responderia ao maquinário maior da sociedade capitalista, em constante tensão, buscando homogeneizar e eliminar as multiplicidades no estriamento.

Haveria, então, um confronto entre a lógica institucional e a lógica discente. Aquela seguindo os parâmetros disciplinares previstos nos currículos pedagógicos e usos dos espaços da instituição escolar, portanto de estriamento, e este se contrapondo ao controle dos professores, quando realizam a agenda institucional, dispondo sempre de uma potência de desterritorialização superior ao estriado (DELEUZE \&GUATTARI, 2004). Isso ocorre devido à estriagem, em seu limite, tornar-se mais homogênea, mais cerrada, formando-se em todas as direções não o seu ideal de estriagem, mas novamente um espaço liso, que se superpõe ao espaço estriado permanecendo diferente dele. Deleuze \& Guattari nos dá como exemplo dessa situação a cidade 


\begin{abstract}
Mas, justamente, o que nos interessa são as passagens e as combinações, nas operações de estriagem, de alisamento. Como o espaço é constantemente estriado sob a coação de forças que nele se exercem; mas também como ele desenvolve outras forças e secreta novos espaços lisos através da estriagem. Mesmo a cidade mais estriada secreta espaços lisos: habitar a cidade como nômade, ou troglodita. Às vezes bastam movimentos, de velocidade ou de lentidão, para recriar um espaço liso. Evidentemente, os espaços lisos por si só não são liberadores. Mas é neles que a luta muda, se desloca, e que a vida reconstitui seus desafios, afronta novos obstáculos, inventa novos andamentos, modifica os adversários. Jamais acreditar que um espaço liso basta para nos salvar. (DELEUZE \& GUATTARI, 1997, p. 189)
\end{abstract}

Assim, apesar da oposição institucional de corpo docente e discente, não há que se acreditar que essencialmente estudantes são contestadores e estão sempre diante de uma ruptura criadora e que professores nunca são agentes transformadores.Pois quando não tratamos essas relações de maneira maniqueísta as mesmas ferramentas podem adquirir características opostas a depender do agenciamento.

\title{
3. O plano de reorganização escolar e pequenas resistências
}

Até aqui pensamos a relação entre corpo docente e corpo discente no espaço institucional escolar. No entanto, quando tentamos compreender as motivações das manifestações e ocupações propostas pelos secundaristas paulistas nos ocorre uma nova relação. Esta com característica muito mais coercitiva e evidente, já que se localiza em espaços mais estriados da disciplina estatal, pois trata-se da ação direta do Estado em suas máquinas mais sincronizadas, a Secretaria de Educação, Diretorias de Ensino e Diretorias escolares. O plano de reorganização escolar foi tornado conhecido através de uma entrevista do então governador Geraldo Alckmin e posteriormente através de nota de seu secretário de educação Herman Voorwald. Com a proposta envolvendo mudanças em pelo menos 94 escolas no Estado de São Paulo foi gerada uma resistência da parte de estudantes organizados em grêmios estudantis, professores não aderentes e comunidades interessadas.

O poder público partindo da prerrogativa de autoridade na organização da educação pública submeteu que "Repensar a estrutura, portanto, é o primeiro passo para legitimar o seu lugar e modificar a cultura e a função social da escola pública.” (VOORWALD, 2015). De tal maneira, talvez, pensou o território escolar apenas em sua produção macropolítica, desviando-se do buscar "pensar o território escolar a partir da luta de forças que constituem as instituições: forças de produção e reprodução; moleculares, micropolíticas e molares" 
Uma ocupação estudantil como máquina de guerra: redes sociais como instrumento de resistência

ROMÃO, 2019

(OLIVEIRA \& FONSECA, 2006, p. 2). O território escolar não seria apenas um lugar, ou uma ideia, sob a qual tudo jaz, antes há os agenciamentos entre corpos, os encontros e desencontros suscitados nos espaços escolares, as memórias, há espaço liso. Tornar numérico ou gráfico, expressar visualmente dados, como a secretaria de educação o fez, foi uma execução de estriamento. Assim, com todo o aparato institucional e midiático capturado criou-se condições para pequenas resistências, o espaço liso do território escolar reorganizando-se em outras multiplicidades.

\section{Redes sociais, registros e territórios}

Para visualizarmos essa percepção do território escolar e das pequenas resistências, partiremos das criações estéticas dos estudantes envolvidos. Interessa-nos mais as fotografias publicadas como registros, para focarmos, dentre as outras possibilidades audiovisuais, como produções plásticas que evidenciam algo do espaço liso. De fato, pensar como essas pequenas resistências podem contribuir com um eixo alternativo aos meios que dominam os veículos de produção e circulação de imagens, destacando-se órgãos do Estado e veículos da mídia de massa. Por rigor e espaço, não pensamos aqui em análises quantitativas, apresentações de grafos e medidas que comprovem a eficiência do espaço da rede social utilizado, senão sua potencialidade.

Desde sua criação até o dia 5 de janeiro de 2016, data da desocupação, foram publicadas 95 imagens, de fotografias a pôsteres. Tratam-se de imagens que vão da frente do prédio escolar, atividades ocorridas internamente, chamamentos para atos públicos, quadrinhos, até manifestações de rua. Destas destacamos as que mostram o uso do espaço escolar. As publicações não têm preocupação rigorosa de apontar autoria, salvo em casos explícitos das imagens terem sido feitas por "fotógrafos profissionais" e ainda assim há imagens da grande imprensa sem serem creditadas. Portanto, as fotografias selecionadas para este artigo são identificadas como apropriadas pelos responsáveis das publicações. 
Figura 1: Sem legenda.

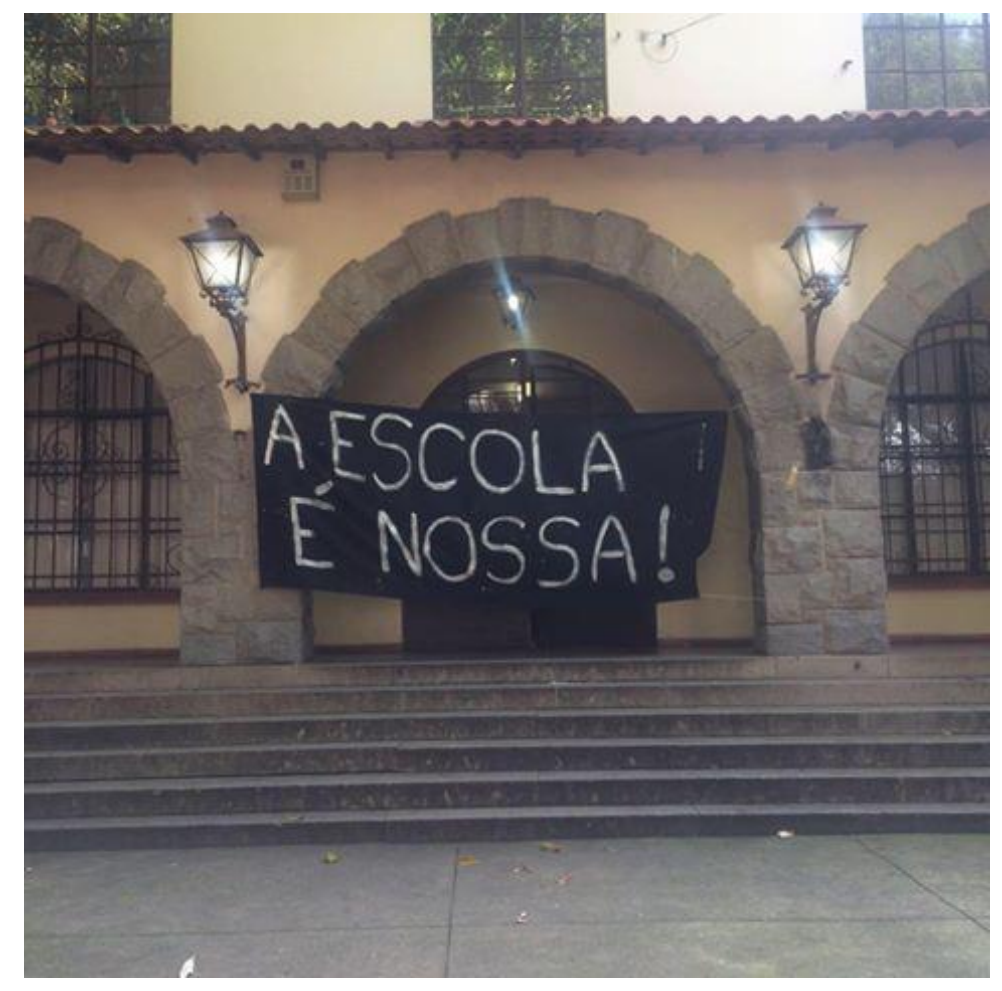

Fonte: Facebook.

A Figura 1 foi utilizada na abertura da página. Não podemos afirmar a data em que foi tirada senão a de sua publicação, dia 17 de novembro de 2015, uma semana após o início da ocupação pelos secundaristas. Ela apresenta a frente do edifício da escola Fernão Dias Paes, sem estudantes, apenas uma faixa negra com a identificação: "A ESCOLA É NOSSA!". Como a faixa foi colocada no centro do enquadramento podemos supor que seja o objeto principal do assunto. Não podemos ver quem fez a faixa, nem quem a colocou, não se põem como assunto, apenas por trás da faixa uma porta semicerrada, cortinas fechadas e iluminação ligada. Será que estão dentro ou fora, a porta entreaberta seria um convite ou um "não entre"? O uso da faixa negra pode ter sido por economia, mas ao mesmo tempo chama atenção para um luto, como utilizada em diversos movimentos sociais, há uma escola deixada para trás, desterritorializada, agora a escola reterritorializada pertence àqueles que colocaram a faixa.

Poderíamos imaginar esse espaço escolar nos termos de Milton Santos como aquele que 
funções e formas que se apresentam por processos do passado e do presente (...) o espaço se define como um conjunto de formas representativas de relações sociais do passado e do presente e por uma estrutura representada por relações sociais que se manifestam através de processos e funções (MILTON SANTOS apud MENDONÇA, 2007, p. 67).

Assim, se o espaço é também um conjunto de relações conflitantes, do uso cultural, político e simbólico, o lugar onde se encontram os secundaristas se transforma a partir da dinâmica de suas ações num espaço de ocupação (MENDONÇA, 2007). Disso podemos observar que se tratando de território, não há o que existe por si, como aquele arregimentado e que se faz crer pelo Estado, mas aquele de que se faz uso. Para Deleuze \& Guattari, numa analogia do Estado ao xadrez, temos

É que o xadrez codifica e descodifica o espaço, enquanto o go procede de modo inteiramente diferente, territorializa-o e o desterritorializa (fazer do fora um território no espaço, consolidar esse território mediante a construção de um segundo território adjacente, desterritorializar o inimigo através da ruptura interna de seu território, desterritorializar-se a si mesmo renunciando, indo a outra parte...). Uma outra justiça, um outro movimento, um outro espaço-tempo. (DELEUZE \& GUATTARI, 1997, p. 9)

O “A escola é nossa!” aponta para essa adjacência, como se o território que não era passasse a ser, o processo de desterritorialização pela ocupação secundarista constitui e estende seu próprio território. Encontramos, se pudermos, as condições para o que Deleuze \& Guattari (1997) chamam de máquina de guerra no espaço. Admitindo que o espaço murado, o cercado, os caminhos cercados, é o espaço do sedentário, aquele que distribui a terra aos homens e faz um espaço estriado, então o espaço liso é marcado por "traços que se apagam e se deslocam com o trajeto" (DELEUZE \& GUATTARI, 1997, p. 43), o espaço do nômade seria, então, aquele que "se distribui num espaço liso, ele ocupa, habita, mantém esse espaço, e aí reside seu princípio territorial"(idem), distribuem-se, os nômades, num espaço aberto, simplesmente vão chegando e aí fazem território, não se vê exatamente de onde vem. Talvez a Figura 1 pudesse servir de metáfora, com sua porta entreaberta, um ver por dentro e não de fora, como se o que se pudesse conhecer da ocupação estudantil fosse apenas possível "ocupando", mesmo que isso significasse pôr em jogo parte da objetividade do analista.

A partir da ocupação secundarista como desterritorialização temporária, surge a pressão por parte do Estado pedindo reintegração de posse no dia 12 de novembro de 2015 (EL PAÍ́S, 2015), tendo sido negado em 24 de novembro, valendo apenas para escolas da capital paulista. Contudo, vemos que sua possibilidade foi concretizada se 
Uma ocupação estudantil como máquina de

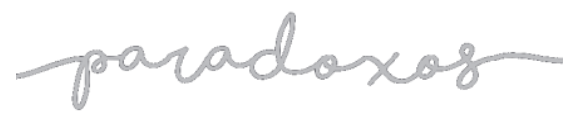

guerra: redes sociais como instrumento de resistência

ROMÃO, 2019

não pela concordância jurídica de direito à ocupação como método de reinvindicação, foi a partir do momento que outras junções de espaços lisos diferentes, outras ocupações estudantis, ocorreram simultaneamente, incluindo também outros movimentos sociais. Caso similar, com as devidas ressalvas e em escala maior, ao utilizado pelo MST Movimentos dos Trabalhadores Rurais Sem-Terra - ao defender ocupações massivas em diversos estados (MENDONÇA, 2007).

O desafio por que passam os secundaristas parece ser como apresentar que o que fazem é legítimo, à sua comunidade e à mídia de massa, está com a função reguladora da memória discursiva. Neste caso, as ocupações estudantis poderiam tentar tensionar o discurso da grande imprensa, concebendo que há nela, em seu complexo, espaços estriado e liso. Assim, tornar noticiável as disputas na agenda midiática trazendo visibilidade aos problemas apontados. De onde poderia surgir a seguinte questão: Como sustentar diante do medo do sedentário, o romper do cotidiano, ainda que temporariamente, do fugaz, do não ser escola, mas ser também escola, da trama de enfrentamentos, de uma pedagogia outra, de pequenas confraternizações, sociabilizações, incluindo aqui as novas conexões em rede de outros estudantes que no passado recente talvez não fossem possíveis dentro dos muros da cidade?

Figura 2: Sem legenda.

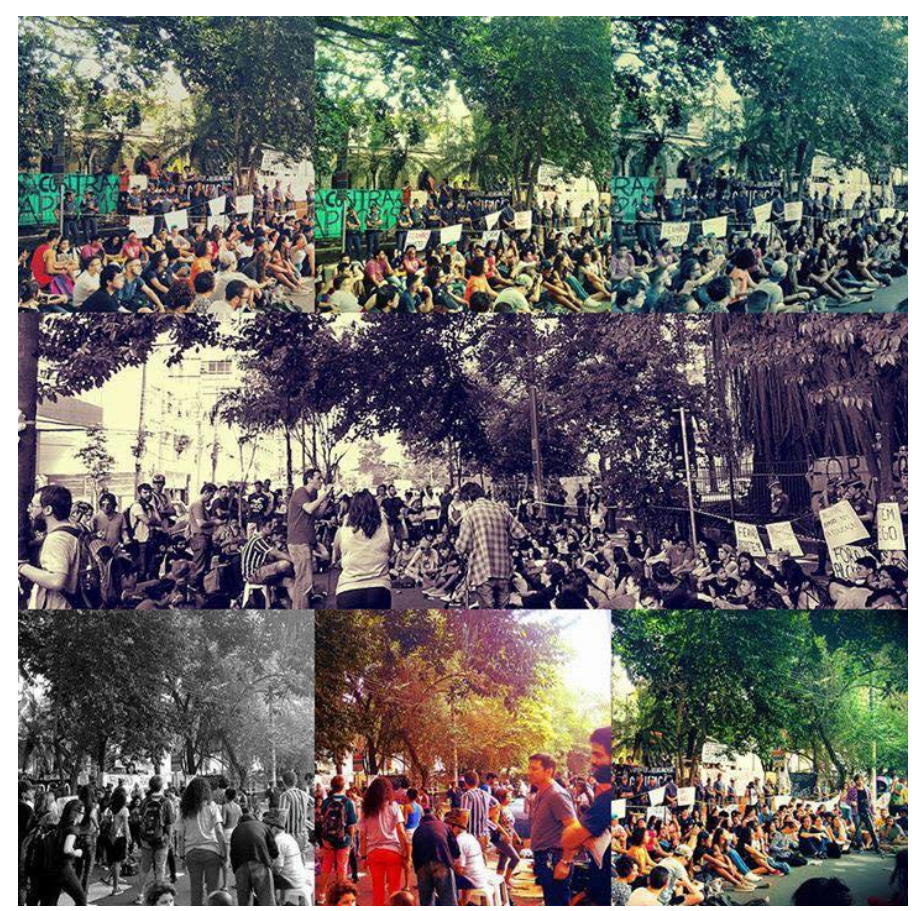

Fonte: Facebook 
Uma ocupação estudantil como máquina de guerra: redes sociais como instrumento de resistência

ROMÃO, 2019

Na Figura 2 já observamos uma composição de sete fotografias, dando a notar a fotografia central em formato panorâmico, apresentando pessoas em frente às cercas da escola. Quem são os estudantes, professores e apoiadores? A escola, agora ocupada, está fora da escola e como se um canal, antes não visto, surgisse para receber o fluxo da cidade.

Na figura 3, abaixo, vemos a proposta de aula "Educação e hierarquia" fora da sala de aula e mais que privada ao espaço institucional em vista de cumprir o currículo pedagógico torna-se aula pública fora do prédio como se tomasse os espaços intersticiais da escola, por onde até então apenas serviam de espaços de orientação e ordenação das cercas internas do prédio escolar.

Figura 3: "Ta rolando aula pública sobre educação e hierarquia com o professor Milton, de sociologia. \#ocupareresistir".

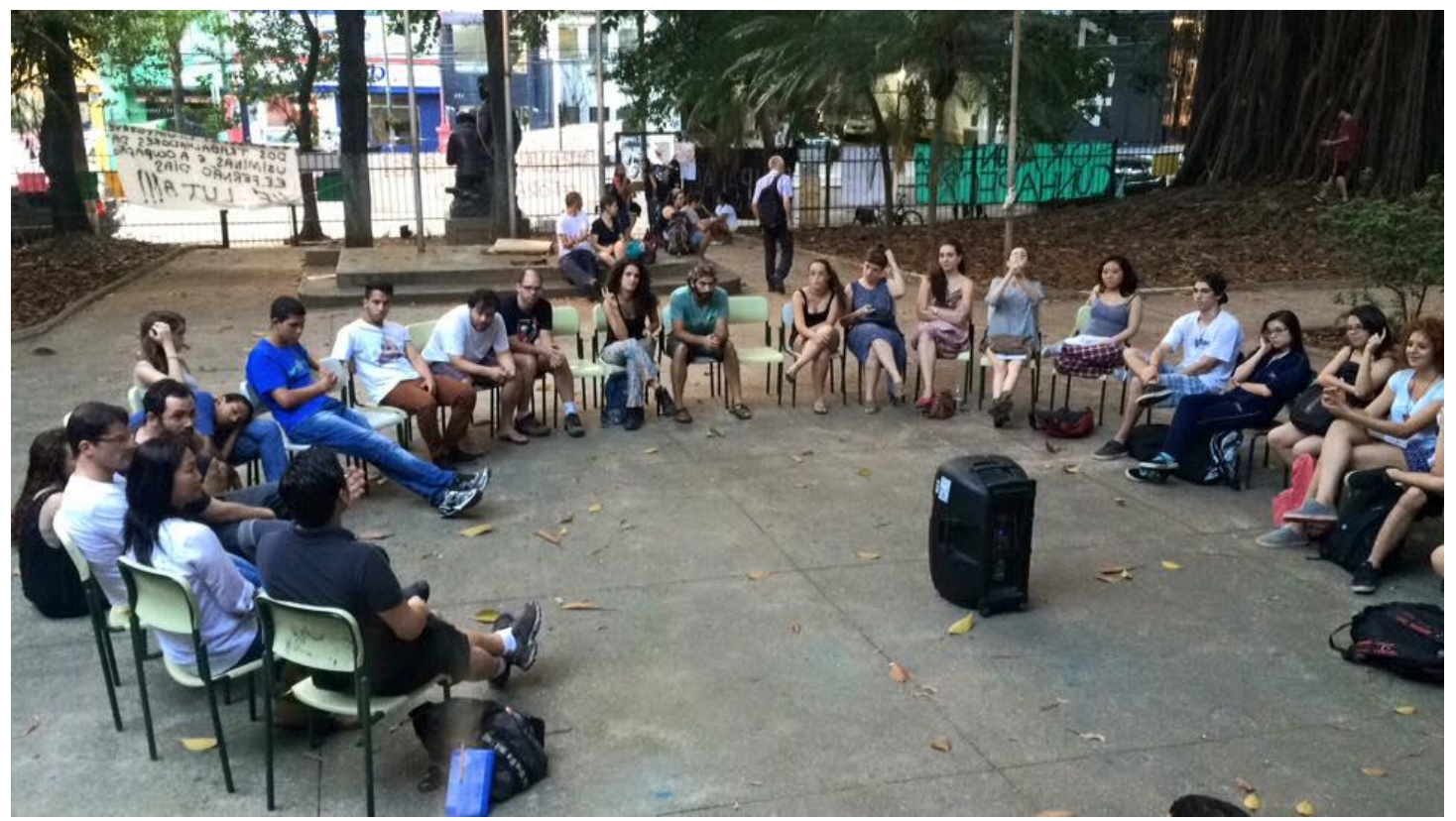

Fonte: Facebook

As grades da escola ocupada são ainda justaposições do estriado, da cerca, mas abertas oferecem à cidade um novo espaço de fluxo e reterritorialização, também um espaço liso dado a encontrar algo de desconhecido.

Como diz Nelson Brissac,

O procedimento do nômade - o sem-teto, o camelô, o favelado, o migrante - é sempre tático. Ele não dispõe de dispositivos de planejamento e coerção: sua ação é ditada pelas necessidades de sobrevivência individual. Ele instrumentaliza tudo o que está ao seu alcance: o morador de rua usa a torneira do posto de gasolina, o camelô toma para si um trecho de calçada, o 
Uma ocupação estudantil como máquina de guerra: redes sociais como instrumento de resistência

ROMÃO, 2019

favelado ocupa áreas junto a autopistas e viadutos e faz ligações clandestinas de luz. Toda a infraestrutura urbana vai sendo requisitada e redirecionada para outros usos. (BRISSAC, 2002, p. 12)

Os secundaristas parecem se utilizar das edificações e entorno como aparatos táticos e protéticos, fluindo através dos espaços antes enclausurantes e de caráter estratégico das políticas de dominação, desterritorializando e reterritorializando. $\mathrm{O}$ teatro, de difícil acesso e muitas vezes desconhecido à maioria, é encenado à noite pelos próprios ocupantes com uma Oficina de Teatro do Oprimido, o deslocar-se e pagar por um show de boa música que dificilmente seria possível é feito ali mesmo no pátio com uma pequena cadeira e amplificador, a figura do ídolo parece desierarquizada, apesar de estar de um lado e público de outro. Como na figura 4 , todos compõem uma mesma paisagem apenas possível a sentir ali sob as condições que a favoreceram.

Figura 3: Tá começando o show do Chico César! \#ocupareresistir.

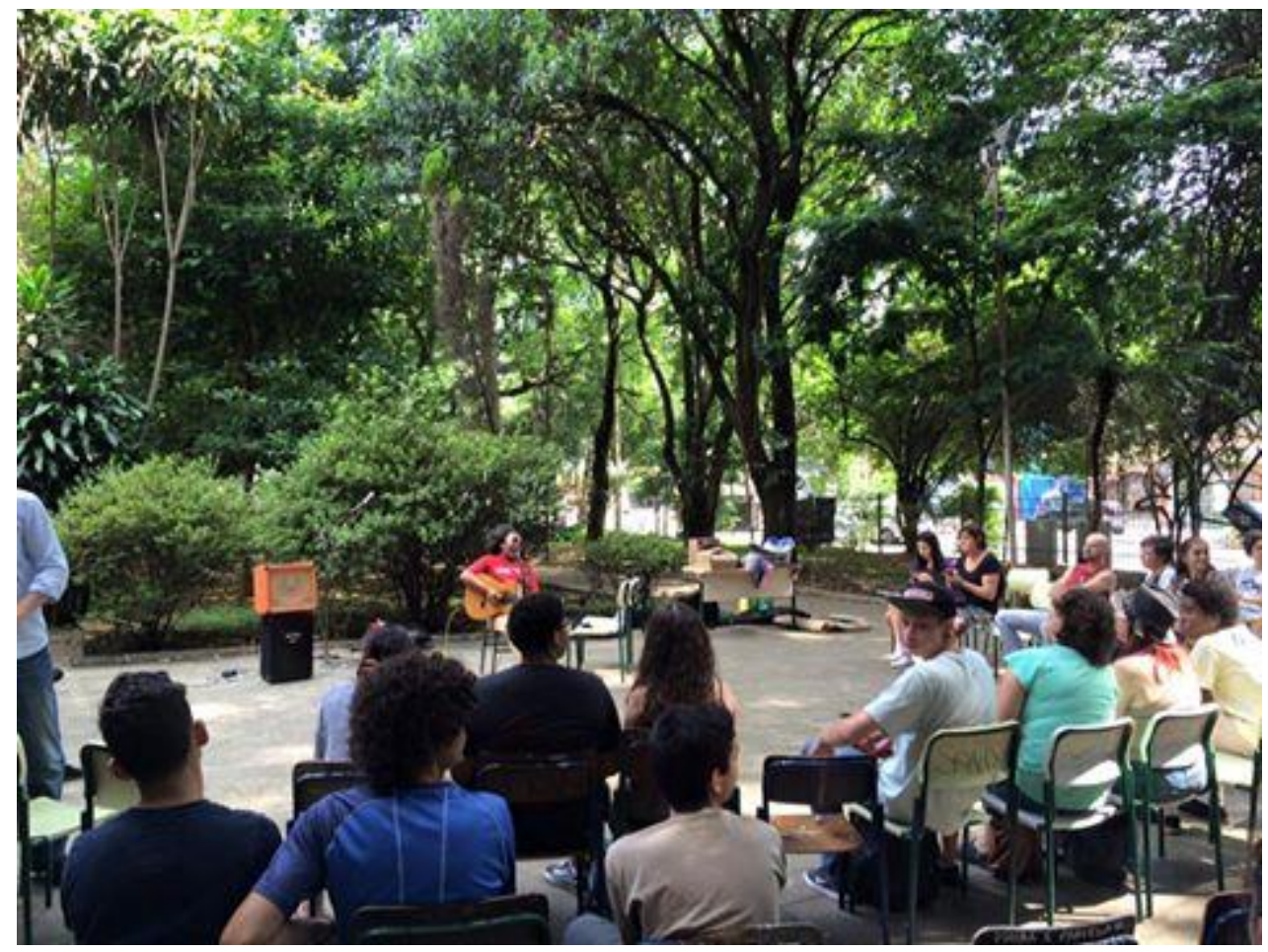

Fonte: Facebook

Assim, pensamos responder a essa perspectiva, também, o uso de redes sociais como mais um espaço, apesar de todo o controle possível por parte dos gerenciadores da rede e mesmo do Estado quando faz vigilância. A geração de secundaristas que ocupou escolas no final de 2015 acostumada a novas tecnologias lançou mão de câmeras de celulares e o garimpo de fotografias na Internet que pudessem utilizar para narrar a seu DOI: http://dx.doi.org/ 10.14393/par-v4n2-2019-48924 Paradoxos, Uberlândia, v. 4, n. 2, p. 53-70, jul./dez. 2019 | 63 
modo os acontecimentos. Não podemos afirmar que o fluxo de suas publicações gerou circulação tão grande quanto faz a imprensa, mas é significativo que manifestações e atos públicos foram organizados rapidamente de maneira massiva, visível pelas passeatas e eventos virtuais, assim como imagens e textos circularam a ponto de repercutir na própria grande imprensa. Contudo, nesse espaço cibernético os ocupantes parecem ter maior possibilidade de potencializar suas máquinas de guerra gerando fluxos desterritorializantes para então trazer territorializações outras.

\title{
5. Fotografias de (re)ocupação e linhas de fuga
}

Sair da escola pela escola. Para Oliveira \& Fonseca o território escolar seria constituído pela interdependência dos espaços estriado e liso, de modo que

\begin{abstract}
São dois planos sobre o mesmo território, sendo que em cada espaço está implícito o outro: não se pode estriar se, em algum momento, não existiu um espaço liso; assim como o espaço liso não é imaculado e não se conserva in aeternum sem estriamentos. Pode-se dizer que o espaço liso é a potência de desterritorialização do território, a capacidade de perder-se, de misturar-se para achar-se novamente em outro estriamento não experimentado; é a capacidade de criação. (OLIVEIRA \& FONSECA, 2006, p. 142)
\end{abstract}

Assim, pensamos, sobretudo a partir das fotografias apresentadas, que o que se almeja são outros estriamentos. O espaço liso não existe a partir do nada, mas de todos os estriamentos identificados no espaço escolar que se sobrepõem a eles. No território desterritorializado e reterritorializado já haveria outras marcas invisíveis que possibilitariam outras direções. A presença de espaços lisos também não significa que não haverá novos estriamentos e trata-se, parece-nos, justamente disso. Criar novas condições para outros estriamentos, já que não existe condição de não haver norma.

Oliveira \& Fonseca falam da experiência estética no "território-escola"

Faz-se necessária uma experiência estética para mover-se pelo espaço liso. Demarca-se o território justamente no devir-expressivo, na emergência das qualidades próprias como cores, odores, sons, manchas, luzes e outras. A configuração do território-escola só pode ser dada a partir de princípios estéticos. (OLIVEIRA \& FONSECA, 2006, p.143)

Essa experiência não se trata de dar forma à matéria, mas dar expressão a ela, no caso de a ocupação-escola "conferir um caráter mutante às marcas da escola a partir de suas qualidades" (OLIVEIRA \& FONSECA, 2006, p. 143). Observando as atividades estudantis e seus registros, surgem marcas dessa experiência ao utilizarem seus próprios corpos como aquilo que move o território-ocupação. 
Uma ocupação estudantil como máquina de pradarag guerra: redes sociais como instrumento de resistência

ROMÃO, 2019

Vejamos as fotografias que demonstram atividades cotidianas da ocupação estudantil.

Figura 4: "Ontem foi dia de mutirão de limpeza! \#ocupareresistir”.

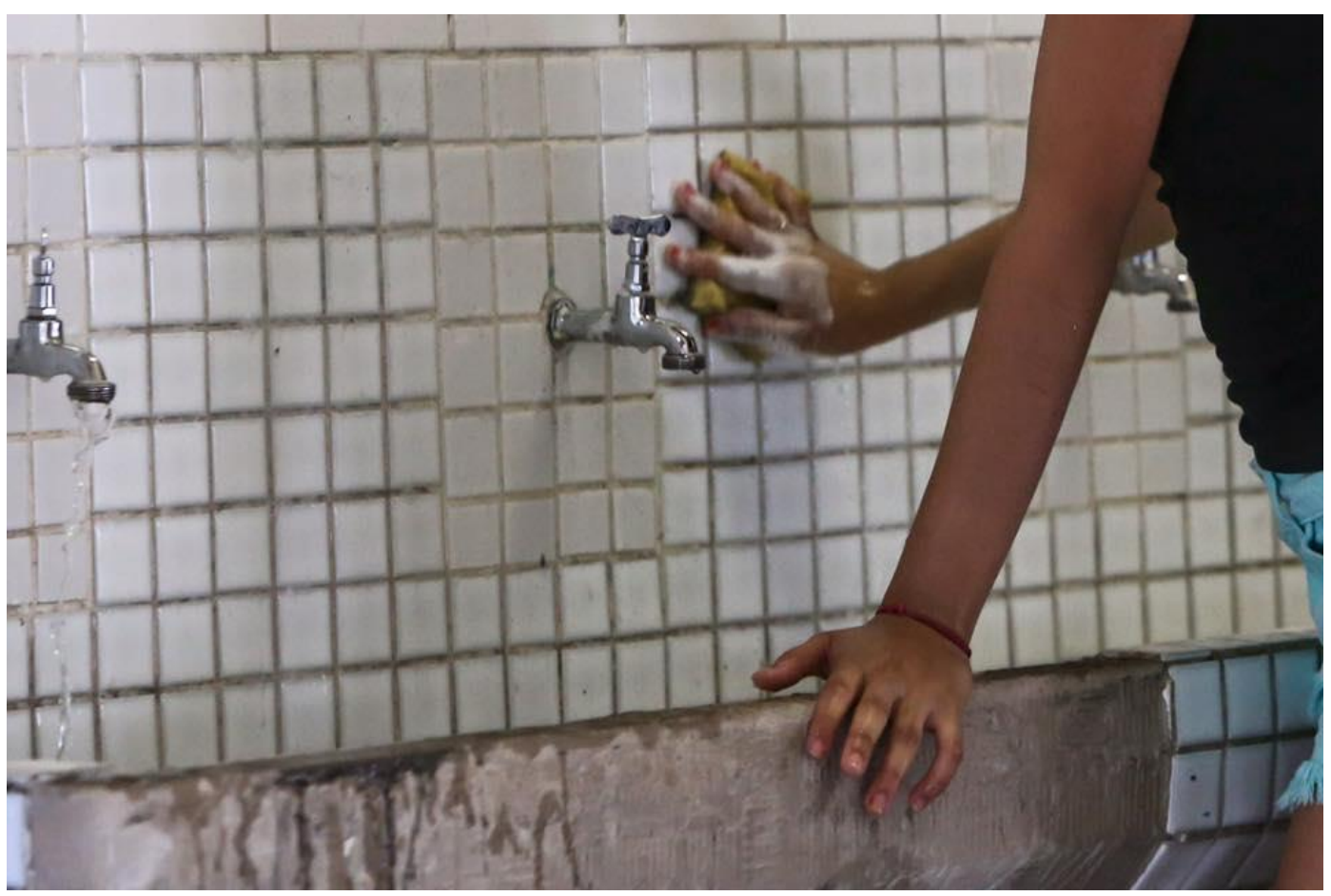

Fonte: Facebook

Figura 6: Preparativos do churrascão no Fernão!

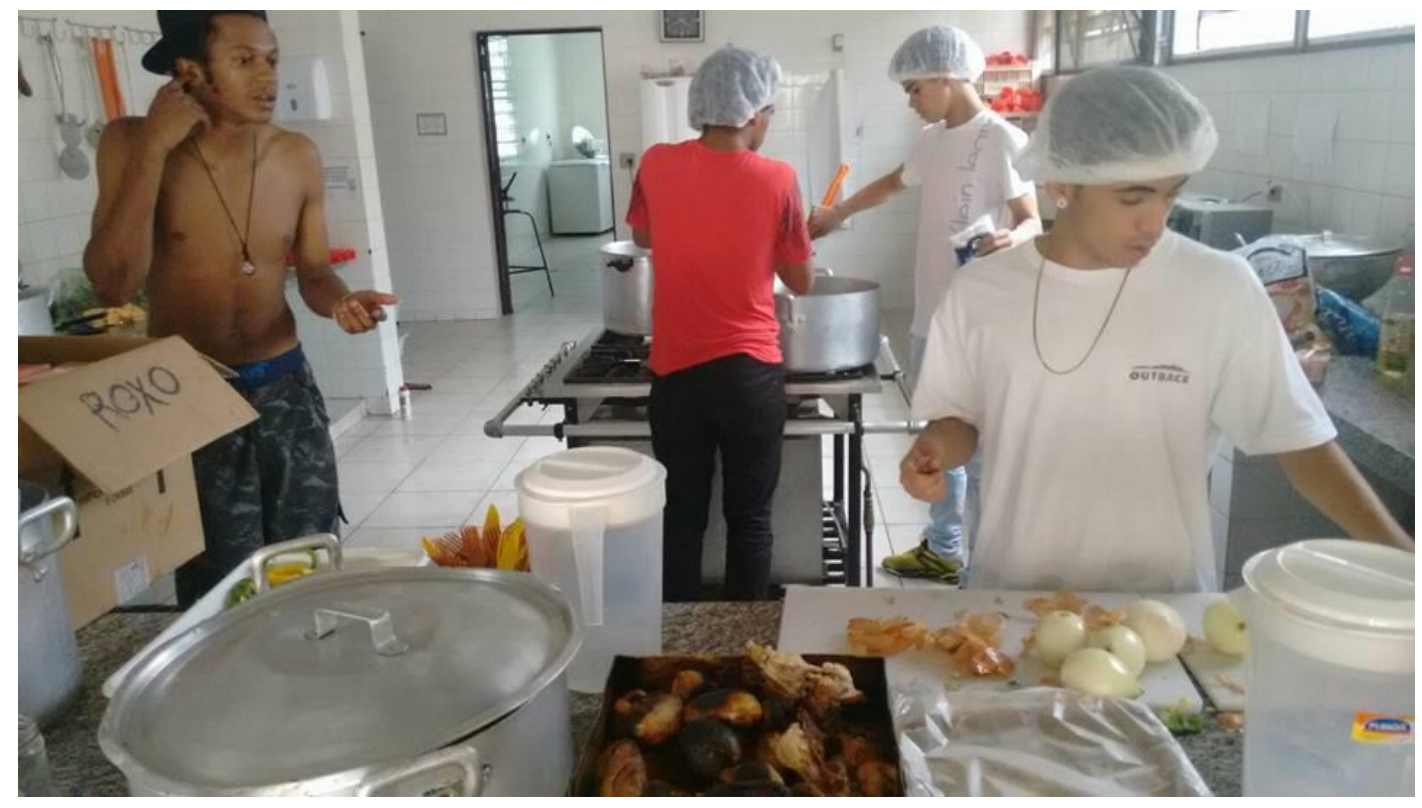

Fonte: Facebook 
Uma ocupação estudantil como máquina de guerra: redes sociais como instrumento de resistência

ROMÃO, 2019

Figura 7: A Chef Paola Carosella (jurada do programa de TV MasterChef) cozinhando na ocupação.

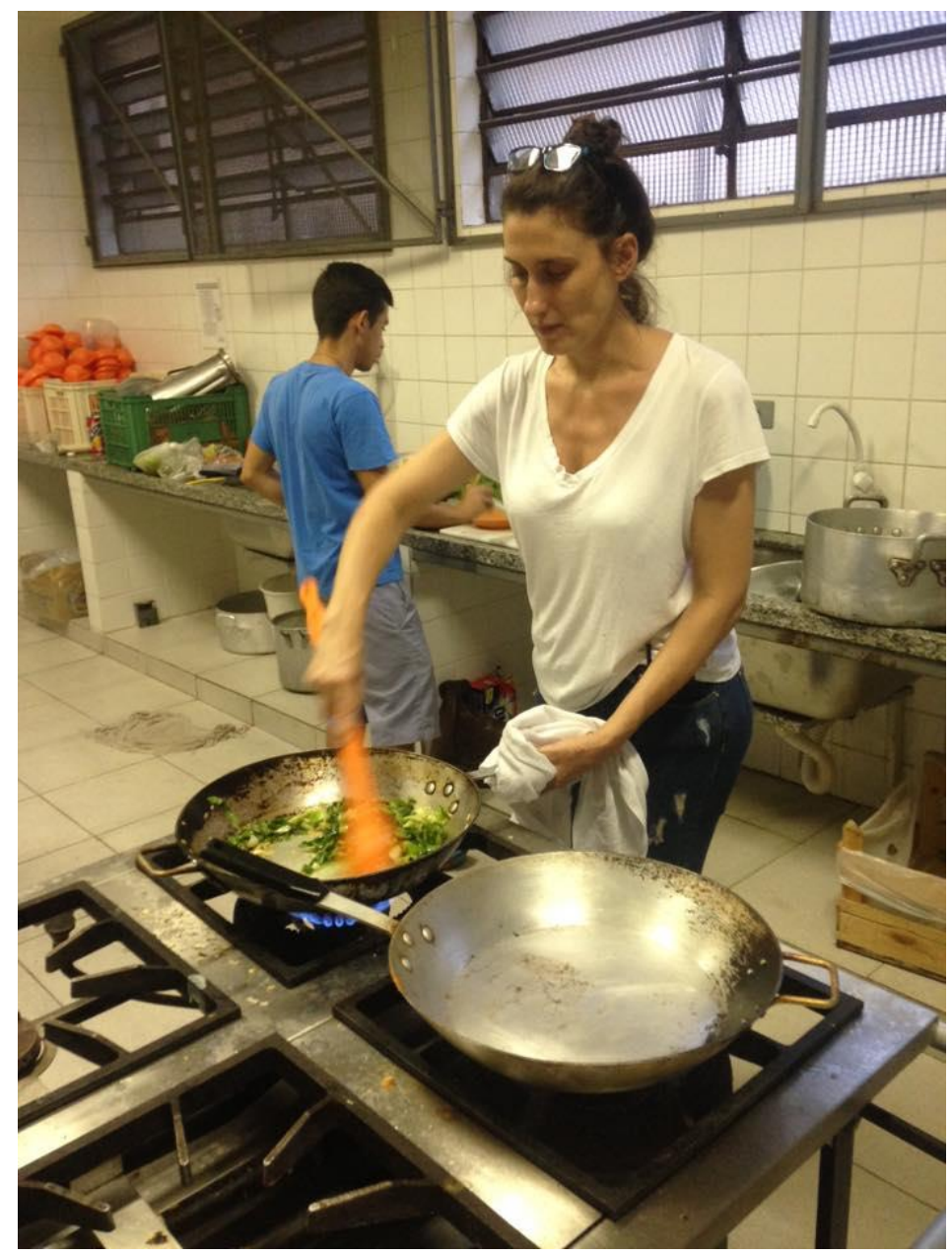

Fonte: Facebook

Como observamos nas Figuras 5 a 7, são as dinâmicas da ocupação que geram o território. Através desses registros publicados, os ocupantes passam a traçar novas narrativas, mostrando que a ocupação estudantil se dá a partir da multiplicidade dos agenciamentos territoriais. Contam sua própria história de não mais apenas estudantes, mas estudantes outros, em movimento, ocupando não um edifício, mas uma paisagem viva, onde flui esse estado necessário de vida. São seus corpos que se reconfiguram nestes espaços "não estudantis" agora também estudantis. A rede social e suas publicações tornam-se aqui mais uma das máquinas de guerra possível, pois se por um lado o Estado trata uma "invasão" escolar como feita por "marginais", por outro tensiona-se com imagens de cuidado com o patrimônio e questionamento do que é e para que serve uma escola. 
Uma ocupação estudantil como máquina de

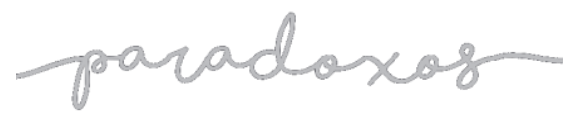

guerra: redes sociais como instrumento de resistência

ROMÃO, 2019

A importância das páginas e suas nomeações como "Escolas de luta" ajudam a organizar uma memória do movimento que dá certa unidade a todos os fluxos, não apenas em São Paulo, mas também em outros estados, como as ocupações de escolas estaduais em Goiás ocorrida em dezembro de 2015. Além disso, outras páginas ajudaram a circular as imagens e informações, formando uma rede, tal qual um organismo onde diversos nós se comunicam, como "O mal-educado" e "Não fechem minha escola". Como se gerassem também uma ocupação virtual e múltiplas operações de montagens em seus estados atuais. Tornando visível um tipo de topografia da máquina escolar.

Por isso, como máquinas de guerra, as ocupações e suas ferramentas, diferentes de terem como objeto a guerra tem como necessidade a luta, emitir quantas de desterritorialização contra o território normalizado, cercado pelo Estado. Essas máquinas agem ao longo das linhas de fuga, reagindo às violências do Estado. As linhas de fuga não são traçadas por aqueles que fogem, no sentido de abandono, mas como criadoras, colocam um espaço liso em deslocamento, assim, não são os ocupantes que definem suas próprias características, mas seu conjunto que os define.

\section{Considerações finais}

Para onde apontam as novas linhas de fuga?

Figura 5: "Nós, estudantes secundaristas ..." 3

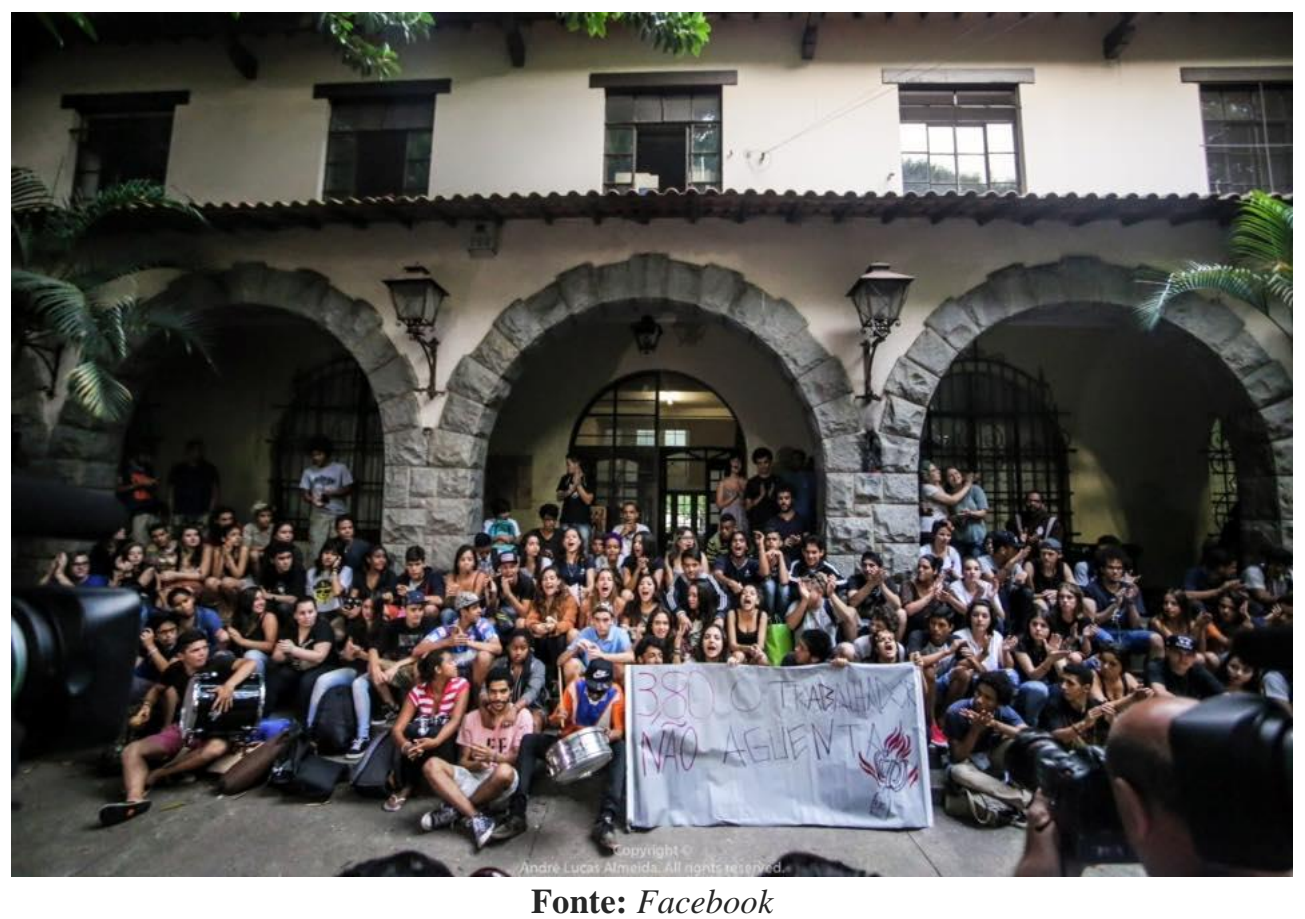

DOI: http://dx.doi.org/ 10.14393/par-v4n2-2019-48924 Paradoxos, Uberlândia, v. 4, n. 2, p. 53-70, jul./dez. 2019 
Diferente da Figura1, temos na Figura 9 uma imagem do encerramento da ocupação da escola Fernão Dias Paes em cinco de janeiro de 2016. A iluminação externa apagada, janelas abertas, luzes internas acesas e dezenas de jovens sentados em frente à escadaria de entrada do edifício. Não é possível dizer se todos são estudantes da escola, mas apenas que estavam envolvidos de alguma forma ou outra na então recente ocupação, ou quem sabe em outras ocupações. Novamente, assim como se constituiu outra paisagem ao longo dos espaços da escola, na imagem, o que se vê são jovens, talvez posando para fotos, mas ao mesmo tempo como se estivessem unidos ao território criado. A escola, já outra escola, parece dar caminho a outras ações possíveis.

Se o Estado pode construir novos agenciamentos, sobrecodificando os novos agenciamentos territoriais, configurando novos agenciamentos maquínicos sobre os corpos, por exemplo ao nomear como Secretário de Educação um jurista, José Renato Nalini, ex-presidente do TJ-SP, exatamente do campo onde a tensão do Estado foi derrotada, o jurídico, então podemos perceber que algo se movimentou. Agora, sabendo que grêmios estudantis são locais eficientes de organização estudantil, partiu do Estado que todas as escolas públicas do Estado de São Paulo tenham essas agremiações, nas palavras do novo secretário, "Vamos intensificar a criação e a dinâmica dos grêmios estudantis, vamos fazer uma ação articulada com as demais secretarias para desenvolver projetos que integrem a educação com uma política de Estado" (SESP, 2016), não sem fazer com que todos os grêmios atuais também tenham novas eleições. Desse modo gerará novos estriamentos com potencialidade de novos espaços lisos.

Mas a Figura 9 parece apontar já para o deslocamento do fluxo, se antes havia uma faixa “A ESCOLA É NOSSA!”, agora surge outra “3,80 TRABALHADOR NÃO AGUENTA". Talvez como um rizoma, que cresce sem comando ou controle, como pontos que se originam em qualquer parte. Segundo Deleuze \& Guattari

\footnotetext{
Diferentemente das árvores ou de suas raízes, o rizoma conecta um ponto qualquer com outro ponto qualquer, e cada um de seus traços não remete necessariamente a traços de mesma natureza, ele põe em jogo regimes de signos muito diferentes, inclusive estados de não-signos. O rizoma não se deixa reduzir nem ao Uno nem ao múltiplo... Ele não é feito de unidades, mas de dimensões, ou antes, de direções movediças. Não tem começo nem fim, mas sempre um meio, pelo qual ele cresce e transborda. Ele constitui multiplicidades. (DELEUZE \& GUATTARI, 2004, p. 15)
} 
Uma ocupação estudantil como máquina de guerra: redes sociais como instrumento de resistência

ROMÃO, 2019

Assim, talvez, da ocupação estudantil outras linhas tenham surgido e por isso mesmo as manifestações contra o aumento das tarifas em São Paulo tenham tido características distintas de outras épocas com novos atores dispostos a fluir por outros espaços invisíveis da cidade, abandonando outros territórios e construindo novas máquinas de guerra. Não entendemos aqui uma relação causal, mas demonstração de que onde há estriamento por parte do Estado, haverá potencialmente espaços lisos a serem sobrepostos, novas paisagens a serem constituídas.

\section{Referências bibliográficas}

BRISSAC, Nelson. Arte/Cidade Zona Leste: máquinas urbanas. Santiago de Compostela: Artedardo, 2011.

DELEUZE, Gilles \& GUATTARI, Félix. Mil platôs: capitalismo e esquizofrenia. Vol.II. São Paulo, Ed. 34. 2004.

DELEUZE, Gilles \& GUATTARI, Félix. Mil platôs: capitalismo e esquizofrenia. Vol.V. São Paulo, Ed. 34. 1997.

PASSETTI, Edson (Org.) A Tolerância e o Intempestivo. Cotia: Ateliê editorial. 2005.

CARVALHO, Alexandre Filordi de \& CAMARGO, A. C. Guattari e a topografia da máquina escolar. ETD. Educação Temática Digital, v. 17, p. 107-124, 2015. Disponível em $:\langle$ https://www.fe.unicamp.br/revistas/ged/etd/article/view/6457〉. Acesso em: 15/01/2019. https://doi.org/10.20396/etd.v17i1.8634821

EL PAÍS. Justiça nega reintegração de posse das escolas ocupadas em São Paulo. Disponível em: <http://brasil.elpais.com/brasil/2015/11/23/politica/1448299485_133769.html>. Acesso em: $18 / 01 / 2019$

HAESBAERT, Rogério \& BRUCE, Glauco. A desterritorialização na obra de Deleuze e Guattari. Revista GEOgraphia, Niterói, ano IV, n.7, p.7-31, 2002. Disponível em: < http://www.uff.br/geographia/ojs/index.php/geographia/article/viewArticle/74> Acesso em: 20/01/2018. https://doi.org/10.22409/geographia2002.47.a13419

MENDONÇA, Kleber S. Ruínas Discursivas. A ocupação midiática sem-terra como máquina nômade. 2007. Tese de Doutorado - PPGCOM, UFF, Niterói, 2007.

NYTIMES. Brazil's Students Occupy Their Schools to Save Them. Disponível em: < http://www.nytimes.com/2015/12/16/opinion/brazils-students-occupy-their-schools-tosave-them.html? r=0> Acesso em: 10/01/2019

OLIVEIRA, Andréia M. \& FONSECA, Tania M. G. Os devires do território-escola: trajetos, agenciamentos e suas múltiplas paisagens. In: Educação e Realidade. Porto Alegre, v. 31, n.2, $2006 . \quad$ Disponível em :< http://seer.ufrgs.br/educacaoerealidade/article/viewFile/6849/4120> Acesso em: 20/01/2019 
Uma ocupação estudantil como máquina de guerra: redes sociais como instrumento de resistência

ROMÃO, 2019

RAMOS, Márcia Elisa Teté (Org.) Estágio / Pesquisa : Ideias históricas de alunos do Ensino Médio. Londrina: UEL. 2013

SAQUET, Marcos A \& DA SILVA, Sueli Santos. MILTON SANTOS: concepções de geografia, espaço e território. Geo UERJ - Ano 10, v.2, n.18, $2^{\circ}$ semestre de 2008. P. 24-42. Disponível em :

$<\mathrm{http}: / / \mathrm{www} \cdot \mathrm{e}-$ publicacoes.uerj.br/index.php/geouerj/article/viewFile/1389/1179>. Acesso em: 20/02/2019. https://doi.org/10.12957/geouerj.2010.1481

SESP. Alunos falam sobre planos e engajamento em ações da escola na volta às aulas. Disponível em $:<$ http://www.educacao.sp.gov.br/noticias/secretario-da-educacao-visitaescola-no-primeiro-dia-de-aula > Acesso em: 15/02/2019. https://doi.org/10.15220/uisunicef-cntry-brasil-2012-po

VOORWALD, Herman. A reorganização paulista e o novo modelo de escola. Disponível em $:<$ http://www.educacao.sp.gov.br/noticias/a-reorganizacao-paulista-e-onovo-modelo-de-escola $>$ Acesso em: 25/01/2019

ZOURABICHVILI, François. O Vocabulário de Deleuze. Trad. André Telles. Rio de Janeiro: Relume Dumara, 2004.

Documentário ACABOU A PAZ - Isto aqui vai virar o Chile - Escolas ocupadas em São Paulo, 1:00:05. https://www.youtube.com/watch?v=cdcFnnlO4k0

Escola de Luta Fernão Dias Paes. https://www.facebook.com/OcupaFernao

O Mal Educado. https://www.facebook.com/mal.educado.sp

Comando das Escolas em Luta. https://www.facebook.com/comando.escolas

Data Recebimento: 28/05/2019

Data Aprovação: 11/2019

\footnotetext{
${ }^{1}$ É necessário ressaltar que outras páginas surgiram e tiveram grande protagonismo na circulação de informações sobre as ocupações e destacam-se ainda hoje em outras pautas.

${ }^{2}$ Nota-se o uso recorrente de ocupações de espaços temporários em frente às catracas das estações de metrô como forma de conseguir liberação das mesmas.

3"Nós, estudantes secundaristas, nos organizamos desde o dia 6 de outubro contra a reorganização imposta pelo governador Geraldo Alckimin. Ficamos ocupados durante 55 dias na escola Fernao Dias Paes, alcançamos juntos mais de 200 ocupações e durante uma semana travamos a cidade. A união de nossas forças nos fez vitoriosos, ganhamos uma batalha mas, ainda não ganhamos a guerra. A LUTA NÃO ACABOU! Todo o apoio as escolas que permanecem ocupadas. De SP á Goiás, de Goiás ao Brasil e do Brasil para o mundo. Deixamos a ocupação, mas continuamos na luta contra todos os ataques que veem de cima, contra reorganização e agora contra o aumento da tarifa."Fotos: André Lucas. Texto lido por estudantes durante a desocupação."
} 